\title{
Electrochemotherapy for the treatment of an incompletely excised subcutaneous low-grade epithelioid hemangioendothelioma in a budgerigar parakeet (Melopsittacus undulatus)
}

\author{
Andrea Lanza ${ }^{1}$, Alfonso Baldi ${ }^{2}$, Giacomo Rossi ${ }^{3}$ and Enrico Pierluigi Spugnini ${ }^{*}$ \\ ${ }^{1}$ Centro Veterinario Gianicolense, Rome, Italy \\ ${ }^{2}$ Department of Environmental, Biological and Pharmaceutical Sciences and Technologies Campania University \\ "Luigi Vanvitelli", Caserta, Italy \\ ${ }^{3}$ School of Biosciences \& Veterinary Medicine, Matelica (MC), University of Camerino, Camerino, Italy \\ ${ }^{4}$ Biopulse srl, Naples, Italy
}

\begin{abstract}
Background: Cutaneous tumors are rarely described in avian and are frequently of viral origin. Solid tumors of vascular origin are seldom reported and usually result in difficult management by surgery alone. We describe the outcome of a subcutaneous low-grade epithelioid hemangioendothelioma (EHE) treated with the combination of surgery and electrochemotherapy.

Case Description: A 10-year-old male budgerigar parakeet (Melopsittacus undulatus) was referred for evaluation of a 2-month non-healing exophytic mass on the left wing. The bird was bright, alert, and responsive, with a $2 \times 1 \mathrm{~cm}$ proliferative lesion on the wing. Signs of discomfort were elicited by the clinical manipulation of the wing; no other abnormalities were detected during physical evaluation. Following hematological and imaging analysis, the parakeet was anesthetized and the mass was surgically removed. The histopathology report came back with a diagnosis of incompletely excised subcutaneous low-grade EHE. A surgical revision was not feasible due to the anatomical location and tumor extension. Adjuvant electrochemotherapy was chosen to increase the chance of tumor control. Two sessions of electrochemotherapy were performed with a 2-week interval between treatments using intralesional bleomycin followed by trains of permeabilizing electric pulses. Side effects were not observed and the parakeet was disease-free for 12 months when he died of acute renal failure.

Conclusion: In lieu of the incomplete surgical excision of the tumor, electrochemotherapy resulted in good local control and cosmetic appearance and should be added to the standard oncological therapies for avian.
\end{abstract}

Keywords: Avian, Biphasic electric pulses, Bleomycin, Electrochemotherapy, Parakeet.

\section{Introduction}

Tumors are frequently reported in budgerigar (Baker, 1980; Reece, 1992). A survey of 257 neoplasms of budgerigars (Baker, 1980) reported that the commonest neoplasms were the testicular tumors. In terms of occurrence, testicular tumors are followed by cutaneous (Owen et al., 2007; Jakab et al., 2013; Nau et al., 2017), mesenchymal (Sasipreeyajan et al., 1988; Gulbahar et al., 2005; Hernández et al., 2012), renal (SimovaCurd et al., 2007), and vascular (Kline et al., 2016; Rossi et al., 2016). Regarding vascular neoplasms in avian, they are most of the times benign hemangiomas associated with subgroup $\mathrm{J}$ avian leukosis virus (Lin et al., 2013). Very few cases of malignant vascular tumors have been reported in different species, including hemangiosarcoma and hemangioendothelioma, with locally aggressive behavior (Sledge et al., 2006; Kline et al., 2016; Rossi et al., 2016). Treatment options aimed at local control are limited to surgical excision of the neoplasms (Baker, 1980; Reece, 1992) and, in selected cases, radiation therapy (Freeman et al., 1999; Swisher et al., 2016). Electrochemotherapy (ECT) involves intra-tumoral injections of chemotherapy (e.g., cisplatin or bleomycin) followed by the application of electric pulses to promote drug absorption (Spugnini et al., 2016). ECT is gaining popularity in exotic animals' oncology (Brunner et al., 2014; Spugnini et al., 2014, 2018; Lanza et al., 2015; 2017; Racnik et al., 2017; 2019). It currently consists of intratumoral injections of chemotherapy agents (usually cisplatin or bleomycin), followed by local delivery of biphasic electric pulses that induce clustering of the transmembrane proteins, thus enhancing drug absorption by cancer cells (Spugnini et al., 2016).

\section{Case Details}

A 10-year-old male budgerigar parakeet (Melopsittacus undulatus) was presented for clinical assessment of a rapidly growing, non-healing exophytic mass on the left wing (Fig. 1A). The bird was bright, alert, 

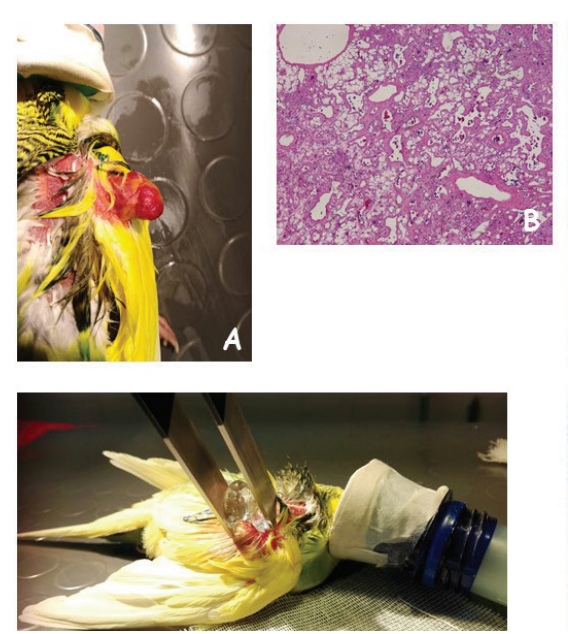

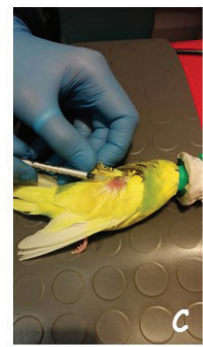

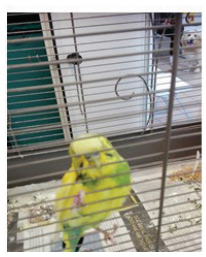

Fig. 1. (A) The patient at presentation showing a large, ulcerate, exophytic mass on the left wing. (B) The histological appearance of the tumor made up by a mixture of areas of epithelioid hemangioendothelioma and areas of low-grade angiosarcoma (H\&E; original magnification $x$ 10). (C) Bleomycin is locally injected in the tumor bed. (D) Permeabilizing electric pulses are administered using plate electrodes. (E) The patient at 3-months follow-up showing no evidence of disease.

and responsive, with a $2 \times 1 \mathrm{~cm}$ proliferative lesion that grew up over the previous 2 months. Signs of discomfort were elicited by the clinical manipulation of the wing; no other abnormalities were detected during physical evaluation. The clinical appearance was suggestive of a neoplastic lesion; therefore, the patient was staged with a complete blood cell count, biochemical analysis, and total body radiographs. The hematological exams were within normal limits, and total body radiographs did not show other underlying pathological conditions or signs of metastatic disease. The parakeet was anesthetized using sevoflurane $2 \%$ in an induction chamber for exotics, followed by maintenance using sevoflurane with a facial mask. The lesion was marginally excised due to its deep connections with underlying tissues and the surgical field was sutured following the guidelines for surgery in avian (Speer, 2015). The bird was discharged on antibiotics and anti-inflammatory drugs (enrofloxacin 5 $\mathrm{mg} / \mathrm{kg}$ PO, BID for 5 days and Meloxicam $0.2 \mathrm{mg} / \mathrm{kg}$ PO SID for 3 days). The excised mass was submitted for histologic evaluation. Histologic sections of the mass were stained with Hematoxylin and Eosin and Van Gieson stain. Histopathologic diagnosis of incompletely excised subcutaneous low-grade epithelioid hemangioendothelioma (EHE) was made. EHE, first described by Weiss and Enzinger (1982), is a distinctive, and malignant vascular neoplasm with indolent behavior in the majority of cases (Weiss and Enziger, 1982), occurring mostly in soft tissues, bone, and skin of extremities in human; it has never been described in an avian species (Mentzel et al., 1997). Its morphology is peculiar and distinguishes itself from common vascular tumors (hemangiosarcoma and lymphangiosarcoma) due to some morphological features such as the constant presence of well-formed multicellular vascular channels, in which a large percentage of lumina show one or maximum two erythrocytes, and some time are occluded by hyaline thrombi. Classically, the vacuolated endothelial cells are arranged in short cords and strands recapitulating the primitive angiogenic cords of the yolk sac (Billings et al., 2003). Although a progressive clinical course with tumor-related fatality has been documented in some human instances, this lesion does not behave as aggressively as a conventional angiosarcoma (Deyrup et al., 2008; Jinghong and Lirong, 2011; Li et al., 2013). In our case, the large, ulcerate, and exophytic mass removed from the left wing (Fig. 1A) showed an infiltrative and characteristic vasculocentric growth, with relatively sharp demarcation, with occasional intravascular expansion and occlusion of larger vessels. The lesion was histologically composed of characteristic epithelioid cells arranged in strands, cords, and nests. In some microscopical fields, there was also often a histiocytoid cellular appearance of some group of pleomorphic, sometimes multinucleate giant cells. Additional fusiform cells were seen associated with some small, neo-formed microvessels. In the central part of the mass, a solid highly cellular area was encountered. The nuclei of neoformed endothelial and fusiform cells were commonly vesicular with small, often distinct nucleoli. Mild nuclear atypia was at least focally observed. In the areas with increased cellular atypia was observed, nuclear pseudoinclusions were generally seen. The growth rate of the tumor was estimated low on the basis of mitoses, less than five per ten high-power field. Generally, an abundant hyaline cytoplasm with variable intracytoplasmic vacuoles was observed in cells constituting the tumor. The prominent feature of the tumor was the constant presence of wellformed multicellular vascular channels, in which a large percentage of lumina were occluded by hyaline thrombi (Fig. 1B). Stroma was absent in highly cellular areas, while a myxohyaline stroma was at least focally present in the most swollen and vascularized areas. In the central part of the tumor, more compact, no necrosis, nor dystrophic calcification, cartilage, or metaplastic bone were ever observed. Hemosiderin deposition and a predominantly marginal inflammatory reaction were also seen. Due to the presence of residual disease in the tumor bed, additional therapy was suggested although the potential for local recurrence of these neoplasms is not clearly defined in avian. Surgical revision was ruled out and the owner declined radiation therapy and opted for ECT. At the time of suture removal, the parakeet was again anesthetized with sevoflurane $2 \%$ and the tumor bed was infiltrated with bleomycin at the concentration of $2.5 \mathrm{mg} / \mathrm{ml}$ (total injected volume 0.1 
$\mathrm{ml}$ (Fig. 1C). Five minutes after the injection, trains of eight biphasic pulses lasting 50 plus 50 microseconds at the voltage of $1,200 \mathrm{~V} / \mathrm{cm}$ (frequency, $1 \mathrm{~Hz}$ ) with eight 300-microsecond interpulses (total treatment time per $\mathrm{cm}, 3.2$ milliseconds) were administered with a clinical electroporator certified for veterinary use (Onkodisruptor ${ }^{\circledR}$ ) (Fig. 1D). The patient was discharged after the session and scheduled for a second and last ECT treatment after 2 weeks. The therapy was well tolerated and toxicosis was not observed. The bird has been disease-free for 12 months (Fig. 1E) when he died of acute renal failure. The owner did not allow to perform a necropsy, to identify possible tumor dissemination.

\section{Discussion}

In avian species, tumors of endothelial origin, such as hemangiomas, hemangioendothelioma, and hemangiosarcomas, have primarily been described in chickens (Soffer et al., 1990) mostly having a viral etiology (Masegi et al., 1993). Scant reports of tumors of endothelial cell origin have been documented in nonpoultry avian species (Suedmeyer et al., 2001; Sledge et al., 2006; Kline et al., 2016; Rossi et al., 2016). A subcutaneous hemangiosarcoma has been reported in a golden pheasant (Suedmeyer et al., 2001) and in a cockatiel (Sledge et al., 2006). In both cases, the tumor rapidly recurred after the surgical excision, resulting in euthanasia. In our case, the incomplete excision of the vascular neoplasm, albeit being classified as a low grade, still might result in tumor recurrence.

ECT, the amalgamation of high-voltage electric pulses and chemotherapy agents, has been shown to be exceedingly effective at controlling incompletely excised cutaneous and subcutaneous tumors regardless of histologic origin (Spugnini and Baldi, 2014). In the current case, bleomycin was chosen because it is the agent most potentiated by ECT. The extensive nature of the lesion prevented wide excision, resulting in marginal tumor removal. Because of limited knowledge on the systemic administration of chemotherapeutics in avian, the budgeteer was locally treated with bleomycin. ECT was well tolerated by the patient and no tumor recurrence was observed in the 12 months post-treatment. In conclusion, ECT is becoming an additional adjuvant modality in exotic animals for locally invasive and/or incompletely excised neoplasms.

\section{Conflict of interest}

Enrico P. Spugnini and Alfonso Baldi are stockholders of Biopulse S.r.l.

\section{References}

Baker, J.R. 1980. A survey of causes of mortality in budgerigars (Melopsittacus undulatus). Vet. Rec. 106, 10-12.

Billings, S.D., Folpe, A.L. and Weiss, S.W. 2003. Epithelioid sarcoma-like hemangioenothelioma. Am. J. Surg. Pathol. 27, 48-57.
Brunner, C.H., Dutra, G., Silva, C.B., Silveira, L.M. and Martins, Mde.F. 2014. Electrochemotherapy for the treatment of fibropapillomas in Chelonia mydas. J. Zoo Wildl. Med. 45, 213-218.

Deyrup, A.T., Tighiouart, M., Montag, A.G. and Weiss, S.W. 2008. Epithelioid hemangioendothelioma of soft tissue: a proposal for risk stratification based on 49 cases. Am. J. Surg. Pathol. 32, 924-927.

Freeman, K.P., Hahn, K.A., Adams, W.H., Jones, M.P. and Petersen, M.G. 1999. Radiation therapy for hemangiosarcoma in a budgerigar. J. Avian Med. Surg. 13, 40-44.

Gulbahar, M.Y., Ozak, A., Guvenç, T. and Yarim, M. 2005. Retrobulbar rhabdomyosarcoma in a budgerigar (Melopsittacus undulatus). Avian Pathol. 34, 486-488.

Hernández, V., Carrera, E., Méndez, A., Morales, J.C., Morales, E. and Sánchez, F.D. 2012. Histopathologic, immunohistochemical and ultrastructural features of a granular cell tumour in an Australian parakeet (Melopsittacus undulatus). Avian Pathol. 41, 437-440.

Jakab, C., Balka, G., Szabára, A., Csaba, C. and Pazár, P. 2013. A case of cutaneous angiolipoleiomyoma (angiomyolipoma) in a budgerigar (Melopsittacus undulatus). Avian Pathol. 42, 511-515.

Jinghong, X. and Lirong, C. 2011. Pulmonary epithelioid hemangioendothelioma accompanied by bilateral multiple calcified nodules in the lung. Diagn. Pathol. 6, 21.

Kline, Z.F., Whittington, J.K. and Coleman, D.A. 2016. Cutaneous Hemangiosarcoma in a Pacific Parrotlet (Forpus coelestis). J. Avian Med. Surg. 30, 152158.

Lanza, A., Baldi, A. and Spugnini, E.P. 2015. Surgery and electrochemotherapy for the treatment of cutaneous squamous cell carcinoma in a yellowbellied slider (Trachemys scripta scripta). J. Am. Vet. Med. Assoc. 246, 455-457.

Lanza, A., Pettorali, M., Baldi, A. and Spugnini, E.P. 2017. Surgery and electrochemotherapy treatment of incompletely excised mammary carcinoma in two male pet rats (Rattus norvegicus). J. Vet. Med. Sci. 79, 623-625.

Li, X.M., Lin, X.Y., Xu, H.T., Yu, J.H., Wang, L., Fan, C.F., Liu, Y. and Wang, E.H. 2013. Mediastinal epitheloid hemangioendothelioma with abundant spindle cells and osteoclast-like giant cells mimicking malignant fibrous histiocytoma. Diagn Pathol. 8, 103.

Lin, Y., Xia, J., Zhao, Y., Wang, F., Yu, S., Zou, N., Wen, X., Cao, S. and Huang, Y. 2013. Reproduction of hemangioma by infection with subgroup J avian leukosis virus: the vertical transmission is more hazardous than the horizontal way. Virol. J. 10, 97.

Masegi, T., Inoue, Y., Yanai, T. and Ueda, K. 1993. An ultrastructural study of cutaneous hemangioma in two chickens. J. Vet. Med. Sci. 55, 185-188. 
Mentzel, T., Beham, A., Calonje, E., Katenkamp, D. and Fletcher, C.D. 1997. Epithelioid hemangioendothelioma of skin and soft tissues: clinicopathologic and immunohistochemical study of 30 cases. Am. J. Surg. Pathol. 21, 363-374.

Nau, M.R., Carpenter, J.W., Lin, D., Narayanan, S. and Hallman, M. 2017. Mucoepidermoid Carcinoma in the Skull of an Orange-winged Amazon Parrot (Amazona amazonica). J. Avian Med. Surg. 31, 225-231.

Owen, H.C., Doneley, R.J., Schmidt, R.E. and PattersonKane, J.C. 2007. Keratoacanthoma causing beak deformity in a budgerigar (Melopsittacus undulatus). Avian Pathol. 36, 499-502.

Racnik, J., Svara, T., Zadravec, M., Gombac, M., Cemazar, M., Sersa, G. and Tozon, N. 2017. Electrochemotherapy with Bleomycin of Different types of Cutaneous Tumours in a Ferret (Mustela Putorius Furo). Radiol. Oncol. 52, 98-104.

Racnik, J., Svara, T., Zadravec, M., Gombac, M., Cemazar, M., Sersa, G. And Tozon, N. 2019. Electrochemotherapy with cisplatin for the treatment of a non-operable cutaneous fibroma in a cockatiel (Nymphicus hollandicus). N. Z. Vet. J. 9, 1-4.

Reece, R.L. 1992. Observations on naturally occurring neoplasms in birds in the state of Victoria, Australia. Avian Pathol. 21, 3-32.

Rossi, G., Galosi, L., Berardi, S., Piano, M.A., Robino, P., Rose, T. and Calabrò, M.L. 2016. Neck Kaposiform haemangioendothelioma in a Fischer's lovebird (Agapornis fischeri). Res. Vet. Sci. 106, $112-115$.

Sasipreeyajan, J., Newman, J.A. and Brown, P.A. 1988. Leiomyosarcoma in a budgerigar (Melopsittacus undulatus). Avian Dis. 32, 163-165.

Sledge, D.G., Radi, Z.A., Miller, D.L. and Lynn, B.S. 2006. Subcutaneous haemangiosarcoma in a cockatiel (Nymphicus hollandicus). J. Vet. Med. A. Physiol. Pathol. Clin. Med. 53,293-295.
Simova-Curd, S., Nitzl, D., Mayer, J. and Hatt, J.M. 2006. Clinical approach to renal neoplasia in budgerigars (Melopsittacus undulatus). J. Small Anim. Pract. 47, 504-511.

Soffer, D., Resnick-Roguel, N., Eldor, A. and Kotler, M. 1990. Multifocal vascular tumors in fowl induced by a newly isolated retrovirus. Cancer Res. 50, 4787-4793.

Speer, B. 2015. Current therapy in avian medicine and surgery, 1st ed. Elsevier, USA.

Spugnini, E.P., Melillo, A., Quagliuolo, L., Boccellino, M., Vincenzi, B., Pasquali, P. and Baldi, A. 2014. Definition of novel electrochemotherapy parameters and validation of their in vitro and in vivo effectiveness. J. Cell Physiol. 229, 1177-1181.

Spugnini, E.P. and Baldi, A. 2014. Electrochemotherapy in veterinary oncology: from rescue to first line therapy. Methods Mol. Biol. 1121, 247-256.

Spugnini, E.P., Azzarito, T., Fais, S., Fanciulli, M. and Baldi, A. 2016. Electrochemotherapy as first line cancer treatment: experiences from veterinary medicine in developing novel protocols. Curr. Cancer Drug Targets 16, 43-52.

Spugnini, E.P., Lanza, A., Sebasti, S. and Baldi, A. 2018. Electrochemotherapy palliation of an oral squamous cell carcinoma in an African Hedgehog. Res. Vet. Forum 9, 379-381.

Swisher, S.D., Phillips, K.L., Tobias, J.R., Cullen, J.M., Gieger, T.L. and Grunkemeyer, V.L. 2016. External beam radiation therapy of squamous cell carcinoma in the beak of an African Grey Parrot (Psittacus timneh). J. Avian Med. Surg. 30, 250-256.

Suedmeyer, W.K., Witter R.L. and Bermudez, A. 2001. Hemangiosarcoma in a golden pheasant (Chrysolophus pictus). J. Avian Med. Surg. 15, 126-130.

Weiss, S.W. and Enzinger, F.M. 1982. Epithelioid hemangioendothelioma. a vascular tumor often mistaken for a carcinoma. Cancer 50, 970-981. 